\title{
The Relationship Between Thrombocyte Lymphocyte Ratio With Tumor Morphology and Alpha Fetoprotein in Patients with Hepatocellular Carcinoma
}

\section{Hepatosellüler Kanser Tanılı Hastalarda Trombosit Lenfosit Orani'nin Tümör Morfolojisi ve Alfa Fetoprotein ile İlişkisi}

\author{
Ümit Karaoğullarından ${ }^{\prime *}$, Hikmet Akkız², Sedef Kuran ${ }^{2}$, Ŏguz Üsküdar ${ }^{2}$, Halil Taşkaynatan ${ }^{3}$, Anıl Delik ${ }^{2,4}$
}

\begin{abstract}
Introduction: The aim of this study was to investigate the relationship between platelet lymphocyte ratio (PLR) and morphological and clinicopathological features of tumor in patients with hepatocellular carcinoma (HCC). Method: Patients diagnosed with HCC by imaging methods (dynamic-triphasic CT and dynamic-MR) and/or tissue sampling (biopsy, resectionor explant) were retrospectively reviewed. Demographic characteristics, etiology, arising from cirrhotic or non-cirrhotic, morphological characteristics of the tumor (tumor diameter, focality, vascular invasion) and; complete blood count, alphafetoprotein (AFP), platelet and lymphocyte counts were calculated at the time of diagnosis. Findings: A total of 223 patients were included in the present study. Of the 223 patients, $185(82.9 \%)$ were male and $38(17.1 \%)$ were female. There was a positive correlation between PLR and AFP (p = 0.05). PLR was significantly higher in patients with portal vein invasion $(\mathrm{p}=0.001)$. PLR values were significantly higher in patients with solitary lesions than those with infiltrative lesions. PLR values were significantly higher in patients with infiltrative tumors than patients with two or more solitary lesions $(\mathrm{p}=0.001)$. There was a positive correlation between maximal tumor diameter (MTD) and PLR in patients with non-infiltrative type tumor ( $\mathrm{p}=0.01$ ). Results: PLR is a cheap and easily applicable marker. It is positively correlated with poor prognostic factors such as vascular invasion, AFP and MTD. PLR can also be used as an additional prognostic biomarker to assess tumor aggressiveness.
\end{abstract}

Key words: Platelet lymphocyte ratio, hepatocellular carcinoma, prognosis.

\section{ÖZET}

Giriş: Bu çalışmada, hepatosellüler karsinom (HCC) tanılı hastalarda platelet lenfosit oranı (PLR) ile tümörün morfolojik ve klinikopatolojik özellikleri arasındaki ilişkinin belirlenmesi amaçlandı. Yöntem: Görüntüleme yöntemleri (dinamik-trifazik CT ve dinamik-MR) ve/veya doku örneklemesi (biyopsi, rezeksiyon veya eksplant) ile HCC tanısı alan hastalar retrospektif olarak incelendi. Hastaların demografik özellikleri, etyolojisi, sirotik veya non-sirotik zeminde gelişmesi, tümörün morfolojik özellikleri (tümör çapı, fokalitesi, vasküler invazyon), tanı anındaki tam kan sayımı, Alfa-fetoprotein (AFP), trombosit ve lenfosit değerleri hesaplandı. Bulgular: Çalışmaya 223 hasta dahil edildi. 223 hastanın 185'i (\%82,9) erkek , 38'i (\%17,1) kadındı. PLR ile AFP arasında pozitif korelasyon $(\mathrm{p}=0,05)$ saptanırken, portal ven invazyonu olan hastalarda PLR'nin istatistiksel olarak anlamlı derecede yüksek olduğu görüldü $(\mathrm{p}=0.001)$. PLR değeri soliter lezyonu olanlarda infiltratif gruptan anlamlı olarak fazlaydı. PLR değeri infiltratif grupta ise iki veya daha fazla nodulü olan gruba oranla istatistiksel olarak anlamlı düzeyde fazlaydı $(\mathrm{p}=0,001)$. İnfiltratif tip tümör dışındaki hastalarda maksimal tümör çapı (MTD) arttıkça PLR'nin de istatistiki olarak anlamlı biçimde arttığı izlendi $(\mathrm{p}=0,01)$. Sonuç: PLR, ucuz ve kolay ulașılabilir bir belirteç olup AFP, vasküler invazyon ve MTD gibi kötü prognostik faktörlerle pozitif korele olarak değişmektedir. Tümörün agresifliğini değerlendirmek için PLR de ek bir prognostik biyomarker olarak kullanılabilir.

Anahtar kelimeler: Trombosit-lenfosit oran1, hepatosellüler kanser, prognoz

Received / Geliş tarihi: 30.12.2019, Accepted / Kabul tarihi: 29.03.2020

${ }^{1}$ Kahramanmaraș Necip Fazıl Șehir Hastanesi, Gastroenteroloji Bölümü, Kahramanmaraş, Türkiye

${ }^{2}$ Çukurova Üniversitesi, Gastroenteroloji Kliniği, Adana, Türkiye

${ }^{3}$ Kahramanmaraş Necip Fazıl Şehir Hastanesi, Tıbbi Onkoloji Bölümü, Kahramanmaraş, Türkiye

${ }^{4}$ Çukurova Üniversitesi, Biyoloji Bölümü, Adana, Türkiye

*Address for Correspondence / Yazışma Adresi: Kahramanmaras Necip Fazıl Şehir Hastanesi, Gastroenteroloji Bölümü, 46050, Kahramanmaraş,

Türkiye, E-mail: ayseasif@gmail.com

Karaoğullarından Ü, Akkiz H, Kuran S,. Hepatosellüler Kanser Tanılı Hastalarda Trombosit Lenfosit Orani’nin Tümör Morfolojisi ve Alfa Fetoprotein ile İlişkisi. TJFMPC, 2020;14(2): 230-235.

DOI: 10.21763/tjfmpc.659799 


\section{GíRiş}

HCC, kansere bağlı ölümlerde dünyada ikinci sırada yer almaktadır. ${ }^{1,2}$ Çoğu hasta, ileri evrede tanı almaktadır. ${ }^{3}$ Birçok kanser patogenez ve progresyonunda sistemik inflamatuar yanıtın çok kritik bir rol oynadığı bilinmektedir. ${ }^{4}$ Yapılan çalışmalar, sistemik inflamatuar yanıtın, hem tümör başlangıç aşamasında hem de progresyonda önemli bir rol oynadığını göstermiştir. ${ }^{5,6}$ Ferritin, trombosit lenfosit oranı (PLR), nötrofil monosit oranı (NMR), nötrofil lenfosit oranı (NLR), C-reaktif protein (CRP) gibi inflamatuar markerların birçok kanserde belirgin olarak arttığı yapılan çalışmalarla belirlenmiştir. $^{7-11}$ Aynı şekilde yapılan pek çok çalışma, HCC'nin inflamatuar zeminde geliştiğini ortaya koymuş ve HCC'de PLR'nin prognostik değerini incelemiştir. ${ }^{12-15}$ Birçok çalışma ise yüksek PLR seviyesi ile kötü prognoz ve kötü klinik ve patolojik bulguların korelasyonunu göstermiştir. ${ }^{16-19}$ Trombositler, vascular endothelial growth factor (VEGF), platelet-derived growth factor (PDGF), fibroblast growth factor (FGF) ve transforming growth factor beta (TGF-beta) ailesi proteinlerini bağlayarak, tümör anjiogenezisinde, hücre proliferasyonunda, migrasyonunda ve metastazda önemli rol oynayan büyüme faktörleri için rezervuar gibi davranmaktadır. ${ }^{20-22}$ Tümör infiltre lenfositler (TILs) ise önemli immun sistem hücreleri olup, anti-tümör özellikleri de mevcuttur. ${ }^{23}$

$\mathrm{Bu}$ çalışmada PLR ile tümörün morfolojik ve klinikopatolojik özellikleri arasındaki korelasyonu belirlemeyi amaçladık.

\section{YÖNTEM}

Çukurova Üniversitesi Tıp Fakültesi Hastanesi’ne 2013-2018 yılları arasında başvuran, 18-85 yaş arası, görüntüleme yöntemleri (dinamik-trifazik CT ve dinamik-MR) ve/veya doku örneklemesi (biyopsi, rezeksiyon ve yaeksplant) ile HCC tanısı alan hastalar retrospektif olarak tarand. Hastaların demografik özellikleri, etyolojisi, tümörün sirotik veya non-sirotik zeminde gelişmesi, tümörün morfolojik özellikleri (tümör çapı, fokalitesi, vasküler invazyon), tanı anındaki kan sayımı, alfafeto protein (AFP) ve trombosit ile lenfosit sayıları bölünerek oranlanan PLR değerleri kaydedildi. Eş zamanlı ikinci bir malignitesi olan ve hematolojik bozukluğu olan hastalar ise çalışmaya dâhil edilmedi.

\section{İstatistiksel Analiz}

İstatistik analizler SPSS Statistics 20 programı kullanılarak yapıldı. Değişkenlerin normal dağılıma uygunluğu analitik yöntemler kullanılarak incelendi. Normal dağılıma uyan parametrik verilerin karşılaştırılmasında bağımsız örneklerde Student T testi, normal dağılıma uymayan verilerin değerlendirilmesinde Mann Whitney U testi kullanıldı. Sürekli değişkenler arasındaki ilişkinin değerlendirilmesinde Spearman bağıntı katsayısı kullanıld1. $\mathrm{p}<0,05$ değeri istatistiksel olarak anlamlı kabul edildi.

\section{BULGULAR}

Çalışmaya toplam 223 hasta dahil edildi. 223 hastanın 185'i $(\% 82,9)$ erkek, 38'i $(\% 17,1)$ ise kadındi. Araştırmaya dâhil edilenlerin yaş ortalaması 64,5 olarak tespit edildi. Yaş ortalamasını cinsiyete göre dağıttı̆̆ımızda, kadınların yaş ortalamasının 66,7 ; erkeklerin ise 63,6 olduğu görüldü. Etyolojik açıdan hastalara bakıldığında en sık 3 nedenin, \%56,9'la Hepatit B virüsünün (HBV), \%15,6'yla Hepatit $\mathrm{C}$ virüsünün (HCV) ve \%9,8'lede Non-Alhocolic Steatohepatitnin (NASH) $(\% 9,8)$ olduğu tespit edildi (Şekil-1). HCC gelişiminin \%61,8'inin sirotik zeminde, \%38,2'sinin ise non-sirotik zeminde olduğu anlaşıldı. Hastaların maksimal tümör çap1 (MTD), tümör fokalitesi, portal ven invazyonu, AFP değerleri incelendi.

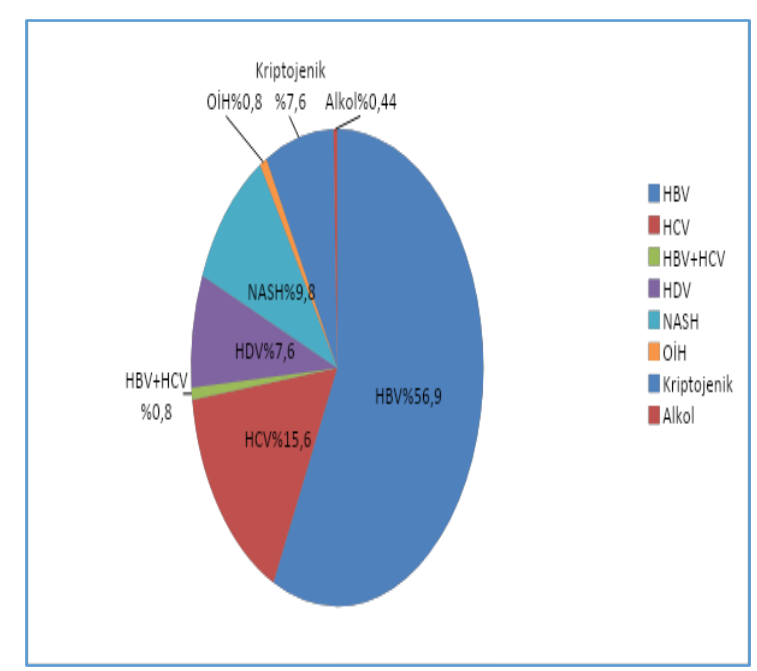

Şekil- 1. Etyolojik dağılım

PLR ile tümör morfolojik özellikleri (MTD, tümör fokalitesi), AFP ve portal ven invazyonu arasındaki ilişki üzerinde duruldu. Veriler incelendiğinde PLO'nun AFP ile pozitif korele olduğu saptandı $(\mathrm{p}=0,05)$ (Tablo-1). PLR ile portal ven invazyonu arasındaki ilişkiye bakıldığında ise portal ven invazyonu olan hastalarda PLR'nin istatistiksel olarak anlamlı derecede yüksek olduğu tespit edildi ( $\mathrm{p}=0.001)$ ( Tablo 2). 


\begin{tabular}{|c|c|c|c|}
\hline \multicolumn{4}{|c|}{ Tablo-1. PLR-AFP korelasyonu } \\
\hline & & PLR & AFP \\
\hline \multirow[t]{3}{*}{ PLR } & $\begin{array}{l}\text { Pearson } \\
\text { Correlation }\end{array}$ & 1 & 0.140 \\
\hline & Sig (2- tailed) & & 0.037 \\
\hline & $\mathrm{N}$ & 223 & 221 \\
\hline \multirow[t]{3}{*}{ AFP } & $\begin{array}{l}\text { Pearson } \\
\text { Correlation }\end{array}$ & $0.140^{*}$ & 1 \\
\hline & Sig (2- tailed) & 0.037 & \\
\hline & $\mathrm{N}$ & 221 & 221 \\
\hline
\end{tabular}
belirlenmiştir (2-tailed). fetoprotein

PLR: Platelet/Lymphocyte Ratio, AFP: Alpha

\begin{tabular}{|l|l|l|l|l|l|}
\hline \multicolumn{7}{|c|}{ Tablo-2. PLR-vasküler invazyon korelasyonu } \\
\hline \multirow{4}{*}{ PLR } & $\begin{array}{c}\text { Vasküler } \\
\text { invazyon }\end{array}$ & & $\begin{array}{c}\text { Mean } \\
\text { Rank }\end{array}$ & $\begin{array}{c}\text { Sun of } \\
\text { Ranks }\end{array}$ & $\begin{array}{c}\text { P } \\
\text { value }\end{array}$ \\
\cline { 2 - 6 } & Yok & 66 & 03.69 & 7213.00 & \\
\cline { 2 - 6 } & Var & 7 & 36.19 & 763.00 & .001 \\
\cline { 2 - 6 } & Total & 23 & & & \\
\hline
\end{tabular}

P değeri için Mann-Whitney U testi kullanılmıştır.

PLR: Platelet/Lymphocyte Ratio

PLR'nin tümör morfolojisi ile olan ilişkisi incelendiğinde, soliter lezyonu olan, 2 adet tümörü olan, multinoduler $(>=3)$ tümör ile infiltratif tip karşılaştırıldığında en yüksek PLR değerinin soliter lezyonu taşıyan grupta olduğu, ikinci sırada ise infiltratif grubun yer aldığ 1 gözlemlendi. İnfiltratif grupta ise iki veya daha fazla nodulü olan gruptan istatistiksel olarak anlamlı düzeyde fazlaydı $(\mathrm{p}=0,001)($ Tablo-3 $)$.

\begin{tabular}{|c|c|c|c|c|}
\hline \multicolumn{3}{|c|}{ Tablo-3. PLR-tümör morfolojisi korelasyonu } \\
\hline \multirow{4}{*}{ PLR } & $\begin{array}{l}\text { Tümör } \\
\text { morfolojisi }\end{array}$ & $\mathbf{N}$ & \multicolumn{1}{|c|}{$\begin{array}{l}\text { Mean } \\
\text { Rank }\end{array}$} & P value \\
\cline { 2 - 4 } & 1 & 133 & 126.65 & \multirow{4}{*}{$<0.001$} \\
\cline { 2 - 4 } & 2 & 18 & 85.28 & \\
\cline { 2 - 4 } & $>3$ & 53 & 84.46 & \\
\cline { 2 - 4 } & İnfiltratif & 19 & 111.61 & \\
\cline { 2 - 3 } & Total & 223 & & \\
\hline
\end{tabular}

P değeri için Chi-Square testi kullanılmıştır.

PLR. Platelet/Lymphocyte Ratio

Değişkenlere baktığımızda, hastalar tümör fokalite açısından gruplandırıldığında MTD açısından gruplar arasında anlamlı farklılık izlenmedi $(p=0,08)$ (Şekil 2). İnfiltratif tip HCC'de radyolojik olarak tümör çapı verilmediği için bu değişken değerlendirilmedi. İnfiltratif tip tümör dışındaki hastalarda MTD ile PLR arasındaki ilişki incelendiğinde, MTD arttıkça PLR'nin de istatistiksel olarak anlamlı derece arttığı görüldü $(\mathrm{p}=0,01)$. Tümör fokalitesi ile MTD arasında ise ilişki saptanmadı $(p=0,08)$.

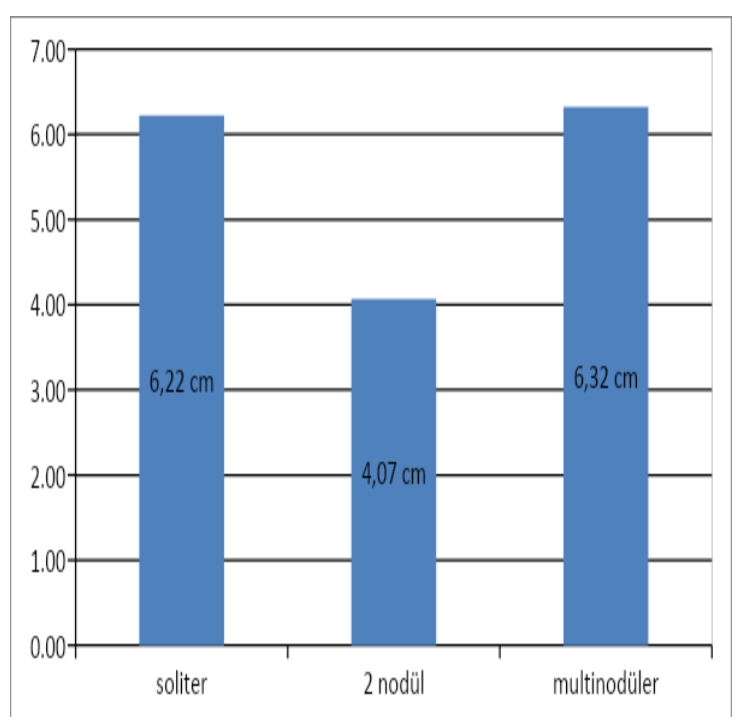

Şekil-2: Tümör fokalitesine göre ortalama maksimal tümör çapları

\begin{tabular}{|l|l|l|l|}
\hline \multicolumn{4}{|c|}{ Tablo-4. PLR-Maksimal tümör çapı korelasyonu } \\
\hline & & PLR & MTD \\
\hline PLR & $\begin{array}{l}\text { Pearson } \\
\text { Korelasyon }\end{array}$ & 1 & $0.250^{* *}$ \\
\cline { 2 - 4 } & Sig (2 tailed) & & 0.0001 \\
\cline { 2 - 4 } & $\mathrm{N}$ & 203 & 203 \\
\hline \multirow{7}{*}{ MTD } & $\begin{array}{l}\text { Pearson } \\
\text { Korelasyon }\end{array}$ & $0.250^{* *}$ & 1 \\
\cline { 2 - 4 } & Sig (2 tailed) & 0.0001 & \\
\cline { 2 - 4 } & $\mathrm{N}$ & 203 & 203 \\
\hline
\end{tabular}

**. Korelasyon anlamlı değeri 0.01 seviyesi olarak belirlenmiştir (2-tailed).

PLR. Platelet/Lymphocyte Ratio, MTD: Maksimal tümör çap1 


\begin{tabular}{|c|c|c|c|}
\hline \multicolumn{4}{|c|}{$\begin{array}{l}\text { Tablo-5. Maksimal tümör çapı-fokalite } \\
\text { korelasyonu }\end{array}$} \\
\hline & & MTD & Fokalite \\
\hline \multirow[t]{3}{*}{ MTD } & $\begin{array}{l}\text { Pearson } \\
\text { Korelasyon }\end{array}$ & 1 & 0.008 \\
\hline & Sig. (2-tailed) & & 0.911 \\
\hline & $\mathrm{N}$ & 203 & 203 \\
\hline \multirow[t]{3}{*}{ Fokalite } & $\begin{array}{l}\text { Pearson } \\
\text { Korelasyon }\end{array}$ & 0.008 & 1 \\
\hline & Sig. (2-tailed) & 0.911 & \\
\hline & $\mathrm{N}$ & 203 & 203 \\
\hline
\end{tabular}

**. Korelasyonun anlamlı değeri 0.01 seviyesi olarak belirlenmiştir (2-tailed).

MTD: Maksimal tümör çapı

\section{TARTIŞMA VE SONUÇ}

İnflamasyon, tümör büyümesinde, invazyonunda ve metastazında hayati rol oynamaktadır. İnflamasyonu göstermekte birçok marker (CRP, PLR, NLR) kullanılmaktadır. ${ }^{24}$ Plateletler tümör anjiogenez ve metastazında rezervuar görevi almakta iken, lenfositler ise immün sistem hücreleri olup anti-tümör özelliğine sahiptirler. ${ }^{25-28} \mathrm{Biz}$ bu çalışmada platelet lenfosit oranındaki değişimin HCC tümör morfolojisi, AFP ve vasküler invazyon ile ilişkisini inceledik. Çalışmamızda PLR arttıkça AFP'nin de korele biçimde arttığını saptadık. Yine PLR'nin, tümör fokalitesi ve maksimal tümör çapı ile pozitif korele olduğunu hesapladık. Çalışmamızda ilginç olan ise PLR'nin en yüksek soliter lezyon grubunda olmasiydı. Bunun sebebi olarak, en yüksek tümör çapının istatistiksel olarak anlamlı olmasa da soliter grupta olmasiyla ilgili olduğunu düşündük. Vasküler invazyonu olanlarda da PLR'nin yüksek olduğunu saptadık.

Plateletler, birçok büyüme faktörü ve inflamatuar faktörler salgılamaktadır. Bu faktörler tümör ve stromal hücrelerin büyümesini indüklemektedir. Ne kadar büyük tümör o kadar fazla tümör yükü anlamına gelmektedir. Ayrıca tümör hücrelerini öldürmede en önemli etkenlerden biri lenfositlerdir. Lenfosit sayısı düştüğünde, haliyle anti-tümör etki de düşmektedir. Biz çalışmamızda trombosit sayısı artmasıyla tümöregenesis, lenfosit sayısının azalmasıyla immunite zayıflaması nedeniyle tümör progresyonu ile sonuçlandığını düşündük.

Tümör ve mikro çevresinden proinflamatuar sitokinler ve büyüme faktörleri kompleks bir şekilde salgılanır. Buna bağlı olarak tümör gelişiminde inflamatuar belirteçler araştırılmıştır. ${ }^{29}$ Xue TC ark. TAKE yapılan HCC'li hastalarda yüksek PLR'nin düşük sağkalım ile ilişkili olduğunu göstermişlerdir. ${ }^{30}$ Lee ark. ise HCC'li hastalarda yüksek trombosit sayısı ekstrahepatik metastaz riskini artırdığını ortaya koymuştur. ${ }^{31}$ Platelet sayısı arttıkça VEGF (vascular endothelial growth factor) ve PDGF (platelet-derived growth factor) sekresyonu artmaktadır; bunların da angiogenesis, hücre proliferasyonu ve tümör metastazında major etkileri mevcuttur. 32,33 Lenfositler, hücre arac1lı anti-tümör immun yanttlarda major rol alırlar. ${ }^{34-36}$ HCC'de düşük lenfosit infiltrasyonu kötü prognozun göstergesidir. ${ }^{37}$

Bizim çalışmamızın bazı sınırlılıkları mevcuttu. İlk olarak, çalışmamızdaki hasta sayısı az ve hastalar retrospektif olarak tek bir merkezde çalışıldı. Bu nedenle, HCC'li hastalar hakkında bilgi toplarken seçim yanlılığını önleyemedik. İkincisi, PLR ilk tanıya giriş sırasındaki tekil ölçümlerle değerlendirildi. Çalışmamızın diğer bir kısıtlılığı ise PLR'nin genel sağkalıma etkisi değerlendirilmemiştir.

Sonuç olarak, PLR ucuz ve kolay ulaşılabilir bir belirteç olup AFP, vasküler invazyon ve MTD gibi kötü prognostik faktörlerle pozitif korelasyon göstermektedir. Tümörün agresifliği değerlendirilirken PLR de ek bir biyomarker olarak kullanılabilir. PLR'nin genel sağkalım, progresyonsuz sağkalım ve diğer prognostik faktörlerle ilişkisini net ortaya koyabilmek için geniş hasta sayısı içeren prospektif randomize çalışmalara ihtiyaç vardır.

\section{KAYNAKLAR}

1. Torre LA, Bray F, Siegel RL, Ferlay J, LortetTieulent J, Jemal A. Global cancer statistics.. CA Cancer J Clin. 2015; 65:87-108.

2. Forner A, Llovet JM, Bruix J. Hepatocellular carcinoma. Lancet. 2012; 379:1245-55.

3. Thomas MB, Jaffe D, Choti MM, Belghiti J, Curley S, Fong Yet al. Hepatocellular carcinoma: consensus recommendations of the National Cancer Institute Clinical Trials Planning Meeting. J Clin Oncol. 2010; 28:3994-4005.

4. Grivennikov SI, Greten FR, Karin M. Immunity, inflammation, and cancer. Cell. 2010; 140:883-99.

5. Grange, J. M., Krone, B., Mastrangelo, G. Infection, inflammation and cancer. International journal of cancer . 2011; 128 :2240-2250

6. Proctor, M. J. et al. A comparison of inflammation-based prognostic scores in patients with cancer. A Glasgow Inflammation 
Outcome Study. European journal of cancer . 1990; 47:2633-2641

7. Facciorusso A, Prete VD, Antonino M, Neve V, Crucinio N, Leo AD et al. Serum ferritin as a new prognostic factor in hepatocellular carcinoma patients treated with radiofrequency ablation. J Gastroenterol Hepatol. 2014; 29:1905-1910.

8. Lee S, Song A, Eo W. Serum Ferritin as a Prognostic Biomarker for Survival in Relapsed or Refractory Metastatic Colorectal Cancer. J Cancer. 2016; 7:957-64.

9. Chen Y, Chen K, Xiao X, Nie Y, Qu S, Gong $\mathrm{C}$ et al. Pretreatment neutrophil-to-lymphocyte ratio is correlated with response to neoadjuvant chemotherapy as an independent prognostic indicator in breast cancer patients: a retrospective study. BMC Cancer. 2016; 16:2352-2358.

10. Wu SJ, Lin YX, Ye H, Li FY, Xiong XZ, Cheng NS. Lymphocyte to monocyte ratio and prognostic nutritional index predict survival outcomes of hepatitis B virus-associated hepatocellular carcinoma patients after curative hepatectomy. J Surg Oncol. 2016; 114:202-10.

11. Gu X, Gao XS, Cui M, Xie M, Peng C, Bai Y et al. Clinicopathological and prognostic significance of platelet to lymphocyte ratio in patients with gastric cancer. Oncotarget. 2016; 7:49878-49887.

12. Matsuzaki K, Murata M, Yoshida K, Sekimoto G, Uemura Y, Sakaida $\mathrm{N}$ et al. Chronic inflammation associated with hepatitis $\mathrm{C}$ virus infection perturbs hepatic transforming growth factor beta signaling, promoting cirrhosis and hepatocellular carcinoma. Hepatology. 2007; 46:48-57.

13. Fan W, Zhang Y, Wang Y, Yao X, Yang J, Li J.Neutrophil-to-lymphocyte and platelet-tolymphocyte ratios as predictors of survival and metastasis for recurrent hepatocellular carcinoma after transarterial chemoembolization. PloS one.2015;10:e0119312.

14. Xue TC, Jia QA, Ge NL, Zhang BH, Wang YH, Ren ZG, et al. Theplatelet-to-lymphocyte ratio predicts poor survival in patients with hugehepatocellular carcinoma that received transarterial chemoembolization. TumourBiol. $2015 ; 36: 6045-6051$.
15. Lai, Q., Lerut, J. Neutrophil and platelet-tolymphocyte ratio as new predictors of dropout and recurrence after liver transplantation for hepatocellular cancer. Transplant international: official journal of the European Society for Organ Transplantation . 2014;27 : 32-41.

16. Goh BK, Kam JH, Lee SY, Chan CY, Allen JC, Jeyaraj P, Significance of neutrophil-tolymphocyte ratio, platelet-to-lymphocyte ratio and prognostic nutrition index as preoperative predictors of early mortality after liver resection for huge $(>/=10 \mathrm{~cm})$ hepatocellular carcinoma. J Surg Oncol. 2016; 113:621-627.

17. 17. Ji F, Liang Y, Fu SJ, Guo ZY, Shu M, Shen SL, Et al. A novel and accurate predictor of survival for patients with hepatocellular carcinoma after surgical resection: the neutrophil to lymphocyte ratio (NLR) combined with the aspartate aminotransferase/platelet count ratio index (APRI). BMC Cancer. 2016; 16:137.

18. Tian XC, Liu XL, Zeng FR, Chen Z, Wu DH. Platelet-to-lymphocyte ratio acts as an independent risk factor for patients with hepatitis B virus-related hepatocellular carcinoma who received transarterial chemoembolization. Eur Rev Med Pharmacol Sci. 2016; 20:2302-2309.

19. Lai Q, Castro Santa E, Rico Juri JM, Pinheiro RS, Lerut J. Neutrophil and platelet-tolymphocyte ratio as new predictors of dropout and recurrence after liver transplantation for hepatocellular cancer. Transpl Int. 2014; 27:3241.

20. Wakefield LM, Smith DM, Flanders KC, Sporn MB. Latent transforming growth factorbeta from human platelets. A high molecular weight complex containing precursor sequences. J Biol Chem. 1988; 263:7646-7654.

21. Gay LJ, Felding-Habermann B. Contribution of platelets to tumour metastasis. Nat Rev Cancer. 2011; 11:123-134.

22. Banks RE, Forbes MA, Kinsey SE, Stanley A, Ingham E, Walters $C$, et al. Release of the angiogenic cytokine vascular endothelial growth factor (VEGF) from platelets: significance for VEGF measurements and cancer biology. Br J Cancer. 1998; 77:956-964.

23. Man YG, Stojadinovic A, Mason J, Avital I, Bilchik A, Bruecher B, et al. Tumor-infiltrating immune cells promoting tumor invasion and 
metastasis: existing theories. J Cancer. 2013; 4:84-95.

24. Coussens LM, Werb Z. Inflammation and cancer. Nature. 2002;420:860-867.

25. Wakefield LM, Smith DM, Flanders KC, Sporn MB. Latent transforming growth factorbeta from human platelets. A high molecular weight complex containing precursor sequences. J Biol Chem. 1988;263:7646-7654.

26. Gay LJ, Felding-Habermann B. Contribution of platelets to tumour metastasis. Nat Rev Cancer. 2011;11:123-134.

27. Banks RE, Forbes MA, Kinsey SE, Stanley A, Ingham $\mathrm{E}$, Walters $\mathrm{C}$, et al. Release of the angiogenic cytokine vascular endothelial growth factor (VEGF) from platelets: significance for VEGF measurements and cancer biology. Br J Cancer. 1998;77:956-964.

28. Man YG, Stojadinovic A, Mason J, Avital I, Bilchik A, Bruecher B, et al. Tumor-infiltrating immune cells promoting tumor invasion and metastasis: existing theories. J Cancer. 2013;4:84-95.

29. Proctor MJ, Morrison DS, Talwar D, Balmer SM, Fletcher CD, O'Reilly DS, et al. A comparison of inflammation-based prognostic scores in patients with cancer. A Glasgow Inflammation Outcome Study. Eur J Cancer .2011; 47: 2633-2641.

30. Xue TC, Jia QA, Ge NL, Zhang BH, Wang YH, Ren ZG, et al. The platelet-to-lymphocyte ratio predicts poor survival in patients with huge hepatocellular carcinoma that received transarterial chemoembolization. Tumour Biol. 2015; 36: 6045-6051.

31. Mlecnik B, Tosolini M, Kirilovsky A, Berger A, Bindea G, Meatchi T, et al. Histopathologicbased prognostic factors of colorectal cancers are associated with the state of the local immune reaction. J Clin Oncol 2011; 29: 610618.

32. Bambace NM, Holmes CE. The platelet contribution to cancer progression. J Thromb Haemost 2011; 9: 237-249.
33. Senzel L, Gnatenko DV, Bahou WF. The platelet proteome. Curr Opin Hematol. 2009; 16: 329-333.

34. Tang X, Huang J, Xiong H, Zhang K, Chen C, Wei X,et al. Anti-tumor effects of the Polysaccharide isolated from tarphochlamys affinis in H22 tumor-bearing mice. Cell Physiol Biochem . 2016; 39: 1040-1050.

35. Wang Y, Liu T, Tang W, Deng B, Chen Y, Zhu J, et al. Hepatocellular carcinoma cells induce regulatory $\mathrm{T}$ cells and lead to poor prognosis via production of transforming growth factor- $\beta 1$. Cell Physiol Biochem . 2016; 38: 306-318.

36. Shen Y, Wei Y, Wang Z, Jing Y, He H, Yuan $\mathrm{J}$, et al. TGF- $\beta$ regulates hepatocellular carcinoma progression by inducing Treg cell polarization. Cell Physiol Biochem. 2015; 35: 1623-1632.

37. Unitt E, Marshall A, Gelson W, Rushbrook SM, Davies S, Vowler SL, et al.Tumour lymphocytic infiltrate and recurrence of hepatocellular carcinoma following liver transplantation. J Hepatol. 2006; 45: 246-253. 